\title{
'É PARA O SEU PRÓPRIO BEM': A DIMENSÃO ÉTICA DAS FERRAMENTAS DE DETECÇÃO DE RISCO DE SUICÍDIO E DA INTERVENÇÃO PATERNALISTA
}

\author{
Alexander Maar ${ }^{1}$ \\ Centro Federal de Educação Tecnológica de Minas Gerais (CEFET - MG) \\ https://orcid.org/0000-0001-8336-7884 \\ E-mail: alexander.maar@web.de
}

\section{RESUMO}

O impedimento de indivíduos acometidos por enfermidade psíquica em risco de suicídio é bem justificado. Mas o impedimento do suicida racional é complicado pelo conflito entre defendermos a vida e defendermos a autonomia, como ilustrado pelas diversas abordagens filosóficas quanto à dimensão ética do suicídio. Argumentaremos que a intervenção paternalista sobre o indivíduo autônomo, desde que de natureza pontual e escopo limitado, é também justificada. Para tanto iremos nos valer da distinção entre autonomia superficial (shallow) e profunda (deep), bem como de fatores complicadores oriundos de literatura médica recente: a questão da ambivalência e o cry for help model. Dedicaremos especial atenção também às implicações éticas de novas estratégias de deteç̧ão de risco que utilizam inteligência artificial aplicada a bases de dados de redes sociais como o Facebook. Embora os dados preliminares sugiram ser ferramentas eficazes, a falta de transparência, regulamentação e consentimento coloca em risco liberdades e direitos civis.

PALAVRAS-CHAVE: Suicídio; Autonomia; Intervenção paternalista; Inteligência artificial; Redes sociais.

\section{'IT'S FOR YOUR OWN GOOD': THE ETHICAL DIMENSION OF SUICIDE RISK DETECTION TOOLS AND OF PATERNALISTIC INTERVENTION}

\begin{abstract}
:
The impediment of individuals affected by mental illness at risk of suicide is well justified. But the impediment to rational suicide is complicated by the conflict between defending life and defending autonomy, as illustrated by the various philosophical approaches to the ethical dimension of suicide. In this article we argue that, insofar as punctual in nature and limited in scope, paternalistic intervention of the autonomous individual is also justified. To do so, we will use the distinction between shallow and deep autonomy, as well as complicating factors from recent medical literature: the question of ambivalence and the cry for help model. We will also pay special attention to the ethical implications of new strategies for risk detection that use artificial intelligence applied to social network databases like Facebook. Although preliminary evidence suggests these are effective tools, their lack of transparency, regulation and consent puts civil liberties and rights at risk.
\end{abstract}

KEYWORDS: Suicide; Autonomy; Paternalistic intervention; Artificial intelligence; Social networks.

\footnotetext{
${ }^{1}$ Doutor(a) em Filosofia pela University of Auckland (U.AUCKLAND), Nova Zelândia. Professor(a) do Centro Federal de Educação Tecnológica de Minas Gerais (CEFET - MG), Belo Horizonte - MG, Brasil.
}

MAAR, Alexander. 'É para o seu próprio bem’: a dimensão ética das ferramentas de detecção de risco de suicídio e da intervenção paternalista. Griot : Revista de Filosofia, Amargosa - BA, v.22 n.1, p.95-116, fevereiro, 2022. 


\section{Introdução}

O suicídio é indubitavelmente um grave problema sanitário. As estatísticas revelam que cerca de 1,5\% de todas as mortes no mundo (entre 800 mil e 1 milhão) são casos de suicídio: uma morte a cada 40 segundos. Para cada tentativa bem-sucedida, estimam-se outras 20 a 25 tentativas malogradas: uma tentativa a cada 3 segundos. Em 2019, o suicídio foi a quarta causa de morte entre a população de 15 a 29 anos (WHO, 2021). No Brasil, 32 pessoas cometem suicídio todos os dias, 12 mil por ano. Para cada suicídio, cerca de 135 pessoas sofrem intenso luto ou são afetadas de alguma forma. Mais de $80 \%$ dos suicídios ocorrem em países de renda baixa ou média (BRASIL, 2020). De acordo com a Associação Brasileira de Psiquiatria (ABP), 50\% dos suicidas brasileiros possuem alguma doença mental não diagnosticada ou conhecida, mas não tratada adequadamente. Outras estimativas sugerem que a relação entre suicídio e doença ou transtorno mental (transtornos de humor) é de 97\% aproximadamente (BERTOLOTE; FLEISCHMANN, 2002). As principais doenças associadas à prática são depressão, transtorno bipolar, transtorno de personalidade limítrofe, e uso de narcóticos. As estatísticas são imprecisas quanto aos suicidas racionais, ou seja, aqueles que tiram a própria vida após deliberação autônoma e na ausência de doença mental incapacitante.

Na comunidade médica e em grande parte da sociedade, existe uma crença compartilhada de que o suicida deve, em geral, ser impedido de pôr fim à própria vida, e de que intervenções são amplamente justificadas se o intuito for a preservação desta. Isso pois, diferentemente de outras decisões equivocada que uma pessoa adulta tenha o direito de cometer - casar-se com uma paixão de Carnaval, por exemplo - o suicídio é final e irremediável. Mas nem todo suicida é igual. Brandt (1975) classifica os suicídios causados por grave e debilitante depressão, por exemplo, como escolhas irracionais, que não emanam de deliberação. Acerca das possiblidades de ação, a tese de Brandt assegura que podemos agir: (a) racionalmente contra nossos próprios interesses (abnegação pessoal); (b) agir irracionalmente contra nossos interesses (caso do suicida acometida de doença psíquica); (c) agir irracionalmente em defesa de nossos interesses (fuga instintiva de perigos); (d) agir racionalmente em defesa de nossos interesses (possibilidade que está em jogo no caso do suicida não acometido por impedimentos psíquico). Nosso interesse está na distinção entre (b) e (d), sobretudo no tocante a legitimidade de qualquer intervenção paternalista.

No caso de (b), sujeitos privados da capacidade de agir em defesa dos próprios interesses, a permissibilidade moral de medidas de intervenção é pouco questionada. Mas no caso de (d), o suicídio racional que ocorre sem impedimento da capacidade de ação racional e autônoma, tal permissibilidade pode ser questionada. Esses são atos de pessoas livres de doença mental incapacitante que decidem pelo suicídio de forma deliberada, calculada e, para alguns, também justificada. Considere os casos de doença terminal e baixa qualidade de vida e os argumentos comumente levantados em defesa da eutanásia e do suicídio assistido. Aqui cabe perguntar, a sociedade tem o dever de impedir o suicida racional da mesma forma que o irracional? Devemos sempre intervir?

A questão do suicídio possui vários complicadores, que influenciam na maneira como respondemos às questões éticas. Muitas pessoas em risco de suicídio não procuram ajuda especializada, nem tampouco revelam seus pensamentos suicidas por medo de sofrerem o estigma de uma doença mental ou temerem intervenção e internação forçada (UNITED STATES, 2001). Outro fator relevante é o de que certos doentes podem não ter a capacidade de interpretar seus estados mentais e se identificar como em risco de cometer suicídio. E muitos médicos têm dificuldade em interpretar sinais de risco ao suicídio em seus pacientes. Além disso, não basta

MAAR, Alexander. 'É para o seu próprio bem': a dimensão ética das ferramentas de detecção de risco de suicídio e da intervenção paternalista. Griot : Revista de Filosofia, Amargosa-BA, v.22 n.1, p.95-116, fevereiro, 2022. 
haver os dados, é preciso que os médicos recebam treinamento para interpretá-los. Um paciente reclama ao seu cardiologista de dores no peito, mas após exames nada se identifica de anormal em termos cardíacos. Podem ser na verdade sintomas de depressão e/ou angústia. Em uma situação assim, não bastaria constar em uma base de dados que tal paciente reclamou de dores no peito em situações passadas.

Com vistas a minimizar o erro diagnóstico, há um crescente interesse no uso de Inteligência Artificial (IA) e na liberação de seu uso junto a bancos de dados digitais como forma de assistir os médicos a aprimorar a detecção de risco e predição de suicídio - permitindo assim intervenções. Os bancos de dados consistem tanto em fichas médicas de pacientes, obtidas graças à crescente integração digital entre hospitais e clínicas (sobretudo, em países que contam com sistemas integrados de saúde, caso do NHS britânico e do SUS brasileiro), quanto no acesso às plataformas de mídia digital como Facebook e Twitter. Nessas plataformas, potenciais suicidas poderiam deixar sinais de alerta a serem identificados por meio de algoritmos e machine learning. $\mathrm{O}$ alcance de sondagem desse tipo seria muito maior do que formas tradicionais de detecção de risco. Contudo, cabe perguntar, é justificado o uso de IA e bancos de dados na prevenção de suicídio, sob o argumento de que tais técnicas são eficazes?

Nesse artigo iremos discutir o argumento em favor da admissibilidade de intervenções curtas, repetidas e localizadas sem prejuízo substantivo ao princípio da autonomia - mesmo no caso de suicídio racional (KELLY; DALE, 2011). Em um segundo momento, ocupar-nos-emos brevemente da questão da permissibilidade moral do uso amplo e irrestrito de algoritmos e big data como instrumento de detecção e prevenção ao suicídio. Um objetivo secundário do artigo será aproximar a filosofia da bibliografia de referência médica, em rápida expansão.

\section{A filosofia e o suicídio}

Albert Camus, em $O$ mito de Sísifo, pronuncia: "Há apenas um problema filosófico realmente sério e esse é o suicídio. Decidir se a vida vale ou não a pena é responder à questão fundamental da filosofia. Todas as demais questões [...] se seguem daí." (1975, p. 3). Em outras palavras, a pergunta fundamental que permeia a obra de Camus é: 'Devo me suicidar?' Sísifo, diante da absurdidade de sua existência, resiste ao suicídio como fuga da inútil tarefa de empurrar uma pedra para o alto da montanha, que cai, e o ciclo se reinicia - uma rotina inútil. $O$ suicídio nada oferece senão uma ilusão de liberdade, uma abdicação de nossa responsabilidade de confrontar esse absurdo (CAMPBELL; COLLINSON, 1988).

A respeito da questão de Camus, 'Devo me suicidar?', Aronson (2017) inteligentemente observa que uma questão mais filosoficamente orientada e melhor formulada seria 'Sob quais condições o suicídio é justificado?'. Seguindo a divisão proposta por Beauchamp (1993), e recentemente revitalizada por Kelly e Dale (2011), as posições filosóficas sobre o suicídio que se atentam a essa pergunta se agrupam em cinco categorias, que ora discutiremos sem ainda tomar posição.

(1) Oposição irrestrita ao suicídio (Kant)

O proponente filosoficamente mais influente dessa abordagem é sem dúvida Immanuel Kant. Em busca pela fundamentação da ética, Kant formula uma sofisticada teoria moral que se coloca diametralmente oposta ao que dirá o utilitarismo no século XIX. Essa teoria, pela sua complexidade, não pode ser sucintamente explicada sem incorrermos em simplificações e

MAAR, Alexander. 'É para o seu próprio bem': a dimensão ética das ferramentas de detecção de risco de suicídio e da intervenção paternalista. Griot : Revista de Filosofia, Amargosa-BA, v.22 n.1, p.95-116, fevereiro, 2022. 
superficialidades. Limitar-nos-emos a tecer comentários pertinentes ao leitor familiarizado com ela.

Kant aceita que procuramos o prazer e evitamos a dor como fins de nossas ações, mas nega que sejamos necessariamente comandados por esses fins. Nega por conseguinte que as capacidades de sentir dor e prazer sejam nossas mestras soberanas. Para Kant, há dois conceitos fundamentais envolvidos na fundamentação da ética, a autonomia - a capacidade de determinar leis para si mesmo - e a dignidade - a capacidade de dar os fins a si mesmo. O conceito de liberdade em Kant, associado à autonomia e à dignidade, é rigoroso e exigente. Quando agimos de modo a buscar o prazer ou afastar a dor não estamos manifestando de forma plena nossa dignidade, pois não escolhemos esse desejo ou apetite em particular; esse nos foi imposto por necessidade natural, isto é, pelo fluxo causal da natureza - um dos exemplos de heteronomia para Kant. Isso não significa dizer que toda ação heterônoma seja não livre - se assim o fosse Kant estaria sujeito à objeção de que uma pessoa que age compelida pelo, digamos, desejo de prazer, não pode ser julgada moralmente. Em Crítica da Razão Prática, Kant promove uma importante distinção entre livre arbítrio e vontade: um sujeito que 'escolhe' deixar-se levar por tais desejos ainda é livre, em certa medida.

Isso nos remete diretamente à questão: Como pode então a vontade ser determinada senão pela natureza (apetites, desejos, fome, sede...)? A resposta está no agir autônomo, isto é, agir segundo uma lei que eu dou a mim mesmo. Quando agimos para realizar inclinações naturais, fazemo-nos de meios para atingir objetivos que não escolhemos. Já o imperativo categórico comanda sem referência a nenhum outro propósito condicionante (produzir prazer ou minimizar a dor). Isso fica claro em sua terceira formulação: "Age de tal maneira que uses a humanidade, tanto na tua pessoa como na pessoa de qualquer outro, sempre e simultaneamente como fim e nunca simplesmente como meio." (KANT, 2007, p. 69). Essa posição decorre do reconhecimento de que a dignidade é um fim em si mesmo, possui valor absoluto, não deve ser usada como meio para a satisfação de vontades, nem das autônomas, nem das heterônomas.

Dito de forma mui simplificada, a busca do prazer e a fuga da dor jamais serão critérios de ação moral para Kant. Mas tampouco serão critérios para a ação imoral: é permitido tomar interesse em agir moralmente, mas não é permitido agir 'por' interesse - salvo se for um interesse necessário à manutenção da vida (alimento, abrigo etc.). Essa posição colide frontalmente com a habitual justificativa do suicídio racional. O suicida, nas palavras de Kant:

\footnotetext{
... para escapar a uma situação penosa, se destrói a si mesmo, serve-se ele de uma pessoa como de um simples meio para conservar até ao fim da vida uma situação suportável. Mas o homem não é ... um objeto que possa ser utilizado simplesmente como um meio, mas pelo contrário deve ser considerado sempre em todas as suas ações como fim em si mesmo. Portanto não posso dispor do homem na minha pessoa para o mutilar, o degradar ou o matar (2007, p. 70).
}

Ao agir a partir de um desejo de pôr fim ao sofrimento ou desalento, ou por não mais possuir qualidade de vida - argumento utilitarista em favor da eutanásia -, o suicida degrada sua dignidade, segundo Kant. Se uma pessoa age contrariamente a certos 'deveres perfeitos' para consigo mesma (um dever que não comporta exceção), incluindo o dever de não se suicidar, trata a si como um meio ao agir 'por' interesse. $O$ mesmo acontece no caso do assassinato para satisfação de algum fim ulterior (assassinato a pagamento). Suicídio e assassinato seriam, de acordo com essa fórmula, ações analogamente imorais.

Se nossa vontade livre e autônoma é fonte do dever moral, como afirma Kant, parece ser contraditório supor que a mesma vontade possa querer destruir o próprio sujeito capaz de escolher

MAAR, Alexander. 'É para o seu próprio bem': a dimensão ética das ferramentas de detecção de risco de suicídio e da intervenção paternalista. Griot : Revista de Filosofia, Amargosa-BA, v.22 n.1, p.95-116, fevereiro, 2022. 
e agir autonomamente. O suicídio constitui a eliminação intencional de algo que possui valor intrínseco, um fim em si mesmo: a vontade. Aniquilar esse sujeito moral é “dispor de si mesmo como um mero meio [e rebaixar] a humanidade na própria pessoa à qual o ser humano foi, todavia, confiado para preservação." (KANT, 2003, 264-265). Seria, portanto, um engano supor que o suicida, ao atentar contra sua própria vida, exerce sua autonomia.

(2) Defesa da santidade da vida

Essa posição contrária à permissibilidade moral do suicídio está intimamente associada à anterior. $\mathrm{O}$ argumento da santidade da vida é claramente de natureza deontológica, uma vez que se refere ao dever de evitar matar (a si e aos outros). Esse argumento reserva a Deus o direito de dar e tirar a vida. O valor absoluto da vida emana de Sua graça.

Importantes teólogos cristãos como Santo Agostinho e São Tomás de Aquino argumentaram que a vida nos é dada por Deus e que, portanto, tentar o suicídio é cometer grave ofensa a Ele, é violar o quinto mandamento da mesma forma que cometer assassinato (BIGGAR, 2004). A crença de que a vida é sagrada opõe-se, de modo geral, a abordagens qualitativas e relativistas em termos de qualidade de vida dos sujeitos. É esse valor intrínseco, argumentam, que comanda nosso respeito incondicional pela vida (BEAUCHAMP, 1993, p. 85). Cumpre acrescentar também que a tese da sacralidade da vida como oriunda de um comando divino independe de qualquer opinião que tenhamos sobre a vida valer a pena, e em quais circunstâncias. Ainda que uma vida irremediavelmente permeada de dor não valha a pena, de uma perspectiva utilitarista, o argumento propugna que devemos continuar vivos em quaisquer circunstâncias. Da mesma forma, se houver determinação divina para morrermos, devemos acatá-la, ainda que nossa vida seja plena de prazer e livre de dor. Há amparo direto para essa posição na Bíblia: Não sabeis que sois templo de Deus e que o Espírito de Deus habita no meio de vós? Não sabeis que sois santuário de Deus e que o seu Espírito habita em vós? Se alguma pessoa destruir o santuário de Deus, este o destruirá; pois o santuário de Deus, que sois vós, é sagrado" (Coríntios 3, 16-17).

Vinculando a visão da santidade da vida à eutanásia, Madre Teresa diz: “A vida é o mais belo presente de Deus para a humanidade, portanto as pessoas e nações que destroem a vida com ... a eutanásia são as mais pobres... nenhuma mão humana deve ser levantada para matar vidas, visto que a vida é a vida de Deus em nós" (CHALIHA; LE JOLY, 1996, p. 174). Em "Declaration on Euthanasia" o Vaticano afirma: "trata-se de violação da lei divina, ofensa à dignidade da pessoa humana, crime contra a vida e atentado à humanidade" (1980 s/p). Assim, assistir alguém ao suicídio, ainda que motivado por um senso de misericórdia, equivocado ou não, é sempre imoral - e equiparável ao homicídio na maioria dos códigos penais.

A oposição teológica ao suicídio possuiu ainda outro desdobramento interessante, que pode ser chamado de 'objeção ao sofrimento valioso'. Essa se refere ao suicídio na forma da eutanásia. Segundo a mesma declaração mencionada: "O sofrimento, especialmente o sofrimento nos últimos momentos da vida, tem um lugar especial no plano salvífico de Deus; é, de fato, uma participação na paixão de Cristo e uma união com o sacrifício redentor que Ele ofereceu em obediência à vontade do Pai" (Ibidem).

Segundo o presente argumento, o suicida racional, ao fugir de uma morte agonizante, priva-se da importante experiência, como aventado em diversos momentos da história da igreja, de compartilhar com Cristo o sofrimento final. Cuidados paliativos para dar conforto ao paciente não são condenáveis, mas teríamos o dever de nos abstermos de qualquer ação que possa abreviar a vida. Por insistir no dever de não matar a si, assim como na proposta de Kant, e por valorizar a experiência do sofrimento final, a abordagem teológica parece chocar-se com o conceito de morte

MAAR, Alexander. 'É para o seu próprio bem': a dimensão ética das ferramentas de detecção de risco de suicídio e da intervenção paternalista. Griot : Revista de Filosofia, Amargosa - BA, v.22 n.1, p.95-116, fevereiro, 2022. 
misericordiosa - evocado por defensores da eutanásia. Todavia, essa abordagem possui uma dimensão mais restrita em relação à proposta de Kant, pois apenas encontrará eventual aceitação entre pessoas de fé.

\section{(3) Defesa da autonomia}

Em conhecido ensaio intitulado On Suicide, David Hume argumenta contra o argumento da santidade da vida. A primeira parte do argumento questiona a suposição de valor absoluto da vida humana: "A vida do homem não possui maior importância para o universo do que a vida de uma ostra" (1777, §9). A seguir, Hume questiona a crença de que apenas a Deus compete tirar vidas: "se de fato a disposição da vida humana fosse reservada ... ao Todo-Poderoso, e o suicídio fosse uma usurpação de seu direito, então seria igualmente criminoso agir pela preservação da vida ou pela sua destruição" $(1777, \S 9)$. Ao cometer suicídio e abreviar a vida, ao invés de perecer por causa natural ou pela mão de outrem, o sujeito coloca-se contra a vontade de Deus. Mas porque não dizer então que o médico, ao tratar do enfermo e prolongar-lhe a vida, também fere a vontade de Deus pela mesma razão? Para Hume, o argumento tomista da sacralidade da vida soará absurdo.

Em um segundo momento, o contra-argumento de Hume se torna um apelo à noção de autonomia e utilidade. Autonomia é entendida como a posse de certas capacidades mentais, tais como "compreender, apreciar o significado das coisas, formar intenções apropriadas, e não estar dominado por irresistíveis forças internas ou externas" (BEAUCHAMP, 1993, p. 84). Essa caracterização é semelhante à forma como a lei pensa a autonomia como condição necessária para atribuição de responsabilidade moral. Esse reconhecimento nos conduz ao princípio da autonomia: "a obrigação de respeitar as capacidades de tomada de decisão das pessoas autônomas, não limitando sua liberdade para efetuar suas escolhas" (Ibidem). Condenar toda e qualquer forma de suicídio parece atentar contra esse princípio.

Permitir o suicídio do mentalmente enfermo, com capacidades cognitivas diminuídas, é sempre imoral. Deixar que um sujeito não autônomo sucumba às forças irresistíveis é inadmissível, pois não é uma defesa de sua liberdade. Esse doente não possui o direito ao suicídio. Aqui a distinção entre suicídio irracional e racional se mostra relevantemente presente. A intervenção é justificada e devida. Ainda que o episódio irracional seja temporário, cabe agirmos no intuito de impedi-lo, pois posteriormente, ao recuperar suas capacidades, poderá decidir contra o ato. Mas, se um sujeito se apresenta mentalmente capaz de deliberação racional, acredita Hume, não pratica crime ou imoralidade ao cometer suicídio: “Um homem que se retira da vida não causa dano à sociedade, apenas cessa de fazer o bem, o que se constituir injúria, é das menores" (1777, $\S 15)$.

Não apenas o suicídio é permissível por não causar dano significativo, como poderá haver situações em que seja desejável e até mesmo nobre cometê-lo. Hume exemplifica o caso inspirado pela história do florentino Filippo Strozzi, que supostamente cometera suicídio para proteger a causa republicana contra os Médici: "Um homem está envolvido em uma conspiração para o interesse público; é preso como suspeito; sabe que [sob tortura] terá seu segredo extorquido dele. Poderia tal pessoa servir melhor ao interesse público do que colocando fim a sua vida miserável?" $(1777, \S 16)$.

Pode, portanto, ser do interesse do indivíduo e da sociedade e do bem maior, que o suicídio seja cometido. E assim como o caso ilustrado, Hume aponta outras situações em defesa da sua permissibilidade. O valor da vida não é, portanto, absoluto, mas relativo ao bem que pode produzir. O suicídio altruísta, servindo-nos de expressão de Durkheim, é tipologia facilmente

MAAR, Alexander. 'É para o seu próprio bem': a dimensão ética das ferramentas de detecção de risco de suicídio e da intervenção paternalista. Griot : Revista de Filosofia, Amargosa - BA, v.22 n.1, p.95-116, fevereiro, 2022. 
ilustrável; considere, por exemplo, um soldado que se joga sobre uma granada para proteger seus companheiros. Essa forma de morte poderia se apresentar não apenas como uma opção, mas como a coisa certa a fazer. Também o suicídio egoísta do prisioneiro condenado que se antecipa à ação do verdugo pareceria permissível, pois serviria igualmente aos interesses da sociedade $(1755, \S 17)$. Esse argumento supõe, entre outras coisas, a justiça da pena de morte - uma tese aberta a inúmeras objeções.

A posição de Hume se mostra precursora do utilitarismo do século XIX e por isso sofre das mesmas fragilidades que o pensamento de Bentham e Mill - entre elas a perene dificuldade de justificar o sacrifício de minorias em prol do bem maior. Não temos o direito, diria Hume, de impedir Strozzi de cometer suicídio em respeito à autonomia e ao bem comum que o suicídio produzirá. Mas ao enaltecer o suicídio altruísta, Hume suscita no leitor duas questões incômodas: (1) para que o suicídio altruísta tenha grande valor, é necessário que a própria vida sacrificada seja valiosa - isso parece sugerir uma noção de alto valor intrínseco da vida humana, o que Hume nega. (2) caso Strozzi decidisse por não se suicidar e enfrentar a tortura, estaria agindo de forma imoral pois em provável prejuízo da maioria? Caso respondamos de forma positiva, criamos condições políticas perigosas que podem aguilhoar nos sujeitos ideias como o dever de se suicidar pela pátria - contra os próprios interesses.

\section{(4) Dever para com os outros}

O argumento em defesa da autonomia, assevera que devemos respeitar a autonomia de sujeitos mentalmente capazes e não lhes cercear a liberdade caso decidam colocar um fim às suas vidas. Teríamos, assim, um dever de zelar pela autonomia de seres racionais, ainda que isso resulte em um ato racional de suicídio. A intervenção involuntária com vistas à prevenção do suicídio é, nesses casos particulares e segundo essa interpretação, não justificada. Mas poder-se-ia contraargumentar que o dever para com os outros associa-se ao dever de beneficência de tal modo que ao proteger a vida do suicidário de suas próprias ações, protegemos sua autonomia e interesses futuros. Assim, o reconhecimento de que temos dever para com os outros não nos assegura a permissibilidade moral da intervenção, nem tampouco a nega.

Há mais uma possível complicação. Battin (1996) formula um caso hipotético, mas verossímil, de um casal em que um dos cônjuges sofre de doença terminal debilitante e dolorosa. Em função do sofrimento, esse sujeito decide racionalmente pelo suicídio. O outro cônjuge, também autônomo e mentalmente capaz, além de piamente religioso e subscrevente ao princípio da santidade da vida, acredita na imoralidade do suicídio. Battin recomenda que as motivações favoráveis aos próprios agentes em questão e as favoráveis a terceiros sejam claramente separadas e consideradas na eventual decisão por uma intervenção. Poderíamos justificar uma intervenção, a depender das circunstâncias do caso, também com base no respeito aos interesses (e na defesa da autonomia) de terceiros. Isto é, ao aceitarmos que temos direitos para com os outros, não resta óbvio que tal dever volte-se apenas aos interesses do suicida.

Kelly e Dale (2011) apresentam ainda outra razão pela qual uma intervenção paternalista poderia ser justificada mesmo no caso do suicida racional: a possibilidade de ambivalência do desejo de se suicidar. Ainda que o suicida seja capaz de ação autônoma, é possível que parte de suas razões, não conscientes, sejam um desejo de obter ajuda, reconciliação ou vingança. É comum que suicidas sejam ambivalentes, que a decisão de pôr fim à vida seja na verdade um clamor de ajuda (cry for help) ou que uma expectativa de intervenção tenha participado, em algum momento, do processo deliberativo. Daí resulta a preferência de alguns autores pelo termo 'suicidário', sugerido por Jean Améry, ou seja, aquele que 'contempla' a possibilidade do suicídio.

MAAR, Alexander. 'É para o seu próprio bem': a dimensão ética das ferramentas de detecção de risco de suicídio e da intervenção paternalista. Griot : Revista de Filosofia, Amargosa - BA, v.22 n.1, p.95-116, fevereiro, 2022. 
É possível também que a psique do suicida seja dual: uma parte deseja morrer, mas a outra viver, ambas em constante tensão e em proporções diferentes ao longo do tempo (BATTIN, 1996). Acrescente-se que ambos os estados mentais, o querer viver e o querer morrer, podem, teoricamente, satisfazer os requisitos para o agir autônomo.

Essa intervenção motivada pelo dever para com outros é acompanhada de considerações importantes. Procurar dissuadir o suicida, a partir do diálogo, e não da intervenção, nunca é imoral. Isso porque aconselhamento e dissuasão engajam diretamente as atividades cognitivas e racionais do suicida (responsáveis pela sua decisão), de modo que qualquer tentativa em o demover da ideia respeita sua autonomia e liberdade futuras (CHOLBI, 2002, p. 252). Uma intervenção por meio do diálogo, desde que o sujeito se disponha a ouvir, poderia também ser caracterizada como paternalista, mas um paternalismo não violento. Intervenções coercitivas aplicadas a suicidas racionais são medidas difíceis de serem justificadas. Intervenções iniciais podem ser justificadas a partir da necessidade de excluirmos a ambivalência. Mas a moralidade de uma contínua e duradoura internação forçada, por exemplo, amparada apenas pelo princípio da beneficência, poderia ser questionada com base no dever de respeitarmos a autonomia e dignidade do suicidário racional.

(5) Cálculo de utilidade

Argumentos utilitaristas contra a moralidade do suicídio comumente apelam para o fato de que esse ato é danoso para a sociedade, pois o fim da vida prematura de um de seus membros poderia, por exemplo, privar a comunidade de sua produtividade econômica e social. Isso é particularmente verdadeiro quando o suicida é um líder ou possui talentos difíceis de serem substituídos (CHOLBI 2011, p. 58-60).

Por outro lado, é possível construirmos um argumento utilitarista em favor do direito de se suicidar. Essa posição fundamenta-se em sua forma clássica na obra de John Stuart Mill. Mill demonstrou ser contrário à intervenção continuada no sentido de impedir um indivíduo livre e mentalmente capaz de pôr fim à própria vida. Apenas intervenções iniciais, exploratórias, com vistas a identificar a causa de um desejo suicida e se assegurar de que a pessoa age de forma intencional e de que tem ciência das consequências de seu ato, seriam permissíveis. Em On Liberty, Mill enuncia: “O único propósito pelo qual o poder pode ser legitimamente exercido sobre qualquer membro de uma comunidade civilizada, contra sua vontade, é prevenir danos a outros... Na parte que apenas diz respeito a si mesmo, sua independência é, por direito, absoluta" (2001, p. 13). Mill era avesso a paternalismos pois acreditava que a concessão de liberdade às pessoas traria consigo melhores condições para o progresso social, bem como para o desenvolvimento do caráter e excelência individuais.

O paternalismo pode ser definido como a limitação intencional da autonomia justificada exclusivamente a partir do objetivo de ajudá-la (DWORKIN, 1992). A intervenção paternalista motivada por tal desejo de beneficência minimiza a necessidade de respeito à autonomia, e autoritariamente impede a ação livre. Sob essa ótica, podemos dizer que abordagens e programas de prevenção do suicídio podem ser, sob certas condições, paternalistas. Seus defensores argumentam que a irreversibilidade do suicídio, combinada com o respeito e valoração da vida, dá origem a um dever de prevenção que supera o respeito à autonomia.

Uma forma mais branda de paternalismo se utiliza exatamente dessa estratégia: a intervenção é justificada temporariamente apenas para verificar se o suicida é racional e autônomo. Sucessivas ou continuadas intervenções não seriam justificáveis. Em seu ensaio Penal Code for India (1990) Mill faz uma longa citação do Código Penal imposto pelos ingleses à Índia,

MAAR, Alexander. 'É para o seu próprio bem': a dimensão ética das ferramentas de detecção de risco de suicídio e da intervenção paternalista. Griot : Revista de Filosofia, Amargosa - BA, v.22 n.1, p.95-116, fevereiro, 2022. 
que distingue entre penas severas a serem aplicadas àqueles que assistem no suicídio de pessoas não competentes (doentes mentais ou crianças), e penalidade menos severas a serem aplicadas àqueles que auxiliam o suicida racional. Mill está chamando atenção aqui para o fato de que a legislação inglesa já distinguia entre o suicida racional e o não-racional. Não se trata de uma defesa do direito de intervir, mas de uma aceitação implícita de que a salvaguarda da vida do suicida não autônomo é incontestável; o mesmo não se pode dizer do suicida racional.

A obra de Mill não contém nenhuma discussão ética diretamente sobre o suicídio, apenas algumas referências esparsas (Utilitarianism II, 9, 13). Há trechos de On Liberty que sugerem uma postura contrária ao suicídio. Veja-se, por exemplo, o argumento de que alguém não poderia vender a si mesmo e tornar-se escravo, pois perderia a liberdade que deve ser protegida: " $O$ princípio da liberdade não requer que sejamos livres para não sermos livres. Poder alienar-se da liberdade não é ser livre" (2001, p. 94). Mill não deixa claro se o suicida pode ou não se valer do princípio da liberdade. É possível que Mill considerasse o suicídio errado no sentido de ser um ato que põe fim à liberdade, ou permissível pelo fato de que o morto não é mais ou menos livre, mas não existente (Cf. MOWER, 2015). A sensibilidade ao tema, detectada pela sua biografia (seu amigo próximo Eyton Tooke se suicidou em 1830, e seu irmão George Grote Mill, em estágios finais de tuberculose, se suicidou em 1853), sugere que Mill tinha certa relutância em tratar do assunto, e quando o fez, não deixou clara sua posição.

\section{Paternalismo pontual}

A posição kantista e a teológica, ao menos a do tomismo clássico, claramente favorecem a visão de que os membros da sociedade estão sempre justificados em proativamente interferir e impedir o suicida (racional ou não). Isso porque a defesa de um valor absoluto, o da vida, sobrepõe-se a outras razões, de ordem instrumental (fugir do sofrimento, gesto altruísta...), segundo a qual o fim antecipado da vida pudesse ser justificado. Na perspectiva teológica, poderse-ia construir ainda o argumento de que temos o dever de evitar o pecado e que, portanto, permitir o suicídio é pecar por omissão, pecar por permitir a destruição de algo que pertence a Deus: o corpo vivo.

Já a posição humeana e a utilitarista, bastante próximas na defesa da autonomia, não se colocam contra toda e qualquer intervenção. Kelly e Dale (2011) argumentam convincentemente que impedir o suicida para verificar as condições mentais presentes e, assegurar-se de que se trata de ação verdadeiramente autônoma, livre de patologias incapacitantes, não apenas é permissível, mas obrigatório. Essa posição é também amparada pela ideia de que temos o dever de preservar o suicida de danos irreversíveis causados a si por uma decisão levada à cabo muitas vezes por impulso. Temos também, é razoável supor, um dever de garantir o bem-estar das pessoas próximas ao suicida. Nenhuma das categorias apresentadas é contra a intervenção pontual e exploratória.

Fora da classificação apresentada temos algumas posições libertárias mais extremas que afirmam que o suicídio é sempre moralmente permissível pois o indivíduo tem o direito de dispor de sua vida como quiser - princípio da autonomia. Essas posições se originam de movimentos antipsiquiatria que veem as intervenções médicas forçadas como coerção injustificada (CHOLBI, 2011, 2017). Para esses libertários extremos não há patologia no exercício da liberdade (SZASZ, 2002). Contudo, a crença de que o suicídio é 'sempre' moralmente permissível parece equivocada, pois ignora os efeitos negativos causados em pessoas próximas: “o direito de autodeterminação é presumivelmente circunscrito pela possibilidade de dano a outros" (CHOLBI, 2011, 2017).

MAAR, Alexander. 'É para o seu próprio bem': a dimensão ética das ferramentas de detecção de risco de suicídio e da intervenção paternalista. Griot : Revista de Filosofia, Amargosa-BA, v.22 n.1, p.95-116, fevereiro, 2022. 
Há abundante evidência de que doenças mentais, como esquizofrenia, e doenças do humor, como depressão, são causas ou gatilhos (pode haver causas anteriores à depressão) de suicídios. Uma das primeiras pesquisas estatísticas que comprova isso é a de Barraclough et. al (1974), que encontrou tais desequilíbrios mentais e emocionais em 93 de um total de 100 suicidas estudados (70\% sofriam de depressão, e 15\% eram alcoólatras). Pesquisas posteriores parecem corroborar os achados estatísticos de Barraclough e apontam alentadíssima correlação entre depressão e suicídio de modo que seria difícil negar à primeira o status de causa da segunda. Mas nem todos os indivíduos deprimidos perdem a capacidade de agir de forma racional e autônoma (KELLY; DALE, 2011). Isso porque muitos casos de depressão são moderados e não incapacitantes da racionalidade. Quando a depressão é a principal razão para o desejo de pôr fim à vida, a racionalidade de se permitir tal ato pode ser contraposta pela verdade aparente de um simples contrafactual: se o suicida racional e depressivo tivesse recebido tratamento adequado, provavelmente não seria mais um suicida. Intervir de forma coercitiva seria uma estratégia possível (embora não a única) com vistas a dar ao indivíduo a oportunidade de deliberar sobre o ato livre de influências patológicas (Cf. CAVANAGH, 2003).

Ainda que tais influências não sejam incapacitantes e impeditivas à autonomia, elas influem nas considerações do indivíduo sobre o valor de sua vida. Poder-se-ia argumentar que a intervenção pontual é uma defesa da autonomia e não um ataque. Isto é, trata-se de impor uma restrição à liberdade do agente em vista de um ganho futuro também em termos de liberdade. Cumpre deixar claro que nossa posição é a de que toda intervenção pontual deve ser uma defesa da autonomia futura, e não uma ação em vista apenas de um benefício. Muitos suicidas racionais, ao receberem tratamento adequado, encontrarão razões para fazer a ambivalência pender para o lado do querer viver. Beauchamp (1993) e Cosculluela (1995) asseveram que, se um indivíduo racional e autônomo, sobre quem foram feitas as devidas intervenções exploratórias (coercitivas ou não) com vistas a aferir a saúde mental e excluir a possibilidade de ambivalência, e a quem foi administrado tratamento, insistir no plano de suicidar-se, seria errado continuar a impedi-lo de forma coercitiva. Concordamos com essa posição, mas acrescentamos que nesse caso estratégias humanizadas não coercitivas devem ser continuamente administradas. A defesa da autonomia do suicidário não conflita com o princípio da beneficência, que nos induz ao paternalismo, desde que após a fase intervencionista inicial não haja restrição importante à liberdade do tentante autônomo.

Há, contudo, um fator complicador que ainda não mencionamos. Estamos fazendo a suposição de que intervenções exploratórias iniciais podem nos informar de forma consistente acerca da autonomia do tentante, afastando a possibilidade de ambivalência. Às vezes isso não é possível. Muitas vezes os suicidas não manifestam sinais de irracionalidade sistêmica ou insanidade, o que dificulta a distinção entre suicidas racionais e não racionais (RADDEN, 1982). Na impossibilidade de aferirmos, com grau satisfatório de precisão, se o tentante é racional, o recurso pontual à intervenção coercitiva pode ser legítimo e necessário. Defendemos a necessidade de um cálculo de custo-benefício entre a gravidade relativa de dois tipos de erro: omitir-se diante de um caso patológico é mais grave do que do impor restrição temporária à autonomia do tentante não patológico. Isso porque o primeiro terá uma chance de recuperar sua autonomia, ao passo que o segundo, ainda que violado em seus direitos, terá mais tempo para reconsiderar sua decisão (COSCULLUELA, 1994, p. 40). A decisão de intervir de forma coercitiva é notadamente tendenciosa (errar para o lado da vida), isto é, procuramos calibrar os mecanismos de detecção e resposta de forma a evitar o erro mais grave.

Como forma de auxiliar esse cálculo de custo-benefício e encontrarmos o equilíbrio adequado entre respeito à autonomia e dever de preservação da vida, Sneddon (2006) diferencia

MAAR, Alexander. 'É para o seu próprio bem': a dimensão ética das ferramentas de detecção de risco de suicídio e da intervenção paternalista. Griot : Revista de Filosofia, Amargosa-BA, v.22 n.1, p.95-116, fevereiro, 2022. 
entre autonomia superficial e autonomia profunda. A primeira seria a liberdade de escolher e agir conforme fins que o indivíduo considera valiosos ou importantes. Essa forma de autonomia não é, em geral, problemática e não constitui problema de saúde pública. A segunda seria a capacidade de refletir sobre o valor atribuído a esses fins ou sobre o valor da vida em geral. É precisamente sobre a autonomia profunda que patologias psíquicas exercem seu efeito negativo, pois o exercício dessa capacidade de valoração subjetiva é dependente das variações de humor do indivíduo. Doenças como a depressão podem levar o sujeito a calcular de forma errônea as probabilidades de experiências futuras de valor e a supervalorizar o sofrimento presente.

Com base na divisão de Sneddon, Nys (2008) sustenta que em um contexto de saúde pública, a autonomia profunda, a capacidade de avaliar os fins de nossas ações, depende da promoção da saúde física e psíquica de uma pessoa. Ao promover de forma sistemática e proativa a prevenção e o tratamento da depressão, por exemplo, sistemas paternalistas estariam na verdade criando condições favoráveis para o pleno exercício da autonomia profunda, além de prevenir, em termos das populações atingidas, grande quantidade de dano. Kelly e Dale (2011) retomam esse ponto de Nys e sustentam que o conceito de autonomia profunda é compatível com medidas de prevenção pontuais e de curto prazo. Já o intervencionismo paternalista prolongado aplicado a indivíduos racionais e autônomos pode ser entendido como uma medida excessiva e autoritária. Na prática, isso ocorre quando indivíduos mentalmente capazes têm sua liberdade indefinidamente restringida - internação involuntária em hospital psiquiátrico, por exemplo com a única justificativa de que estão em risco de cometerem suicídio. Essa estratégia de prevenção extrema sofreu críticas na literatura relevante e sua defesa é problemática (BATTIN, 1996). Kelly e Dale (2011) referem-se à intervenção continuada e de longo prazo como abuso injustificável das liberdades civis. Curtice (2008), por sua vez, argumenta que a detenção prolongada de eventuais suicidas racionais pode ser qualificada como cruel e desumana se for estabelecido que isso lhes causa intenso sofrimento mental.

O suicídio é danoso à sociedade, às famílias e aos indivíduos. Com exceção de certas posturas libertárias extremas, as posições filosóficas se aglutinam em favor da defesa da vida e contra o direito ao suicídio, pelo menos em um primeiro momento. Há acordo quanto à permissibilidade e obrigação de intervirmos de forma preventiva nos casos em que a autonomia se encontra prejudicada por patologia psíquica. Há também relativo consenso na comunidade médica e na filosofia moral de que suicidas racionais precisam ser inicialmente impedidos de forma pontual e específica, a fim de se eliminar a possibilidade de ambivalência. A necessidade dos sistemas de saúde de adotarem políticas preventivas que minimizem o dano geral é bem justificada - ainda que disso resultem casos de pontual intervenção coercitiva sobre indivíduos racionais pelo fato de haver forte relação entre saúde e capacidade de deliberação autônoma profunda.

\section{AI e big data}

É desejável que as ferramentas de prevenção ao suicídio sejam eficazes, e que os mecanismos de resposta sejam proporcionais ao risco detectado. Encarregar apenas os agentes de saúde de identificar aqueles em risco de suicídio, a estratégia tradicional, não é um método eficaz. Por essa razão, cresce o interesse em torno do uso de inteligência artificial e técnicas analíticas na detecção de indivíduos e grupos em risco. A inteligência artificial tem por objetivo permitir que sistemas de alta capacidade repliquem a inteligência humana aplicada a um objetivo específico, no caso, predição de risco. Essa tecnologia é antiga, mas apenas em anos recentes passou a ser aplicada de forma sistemática e rigorosa na detecção de risco de suicídio (MCKERNAN et al, 2018). Em parte, a novidade da aplicação se explica pelas importantes e relativamente recentes

MAAR, Alexander. 'É para o seu próprio bem': a dimensão ética das ferramentas de detecção de risco de suicídio e da intervenção paternalista. Griot : Revista de Filosofia, Amargosa-BA, v.22 n.1, p.95-116, fevereiro, 2022. 
transformações na forma de armazenamento e acesso a informações relevantes. Há duas grandes bases de dados a serem exploradas. Com base na tipologia dos dados D'Hotman et al (2020) agrupam as possibilidades em duas categorias: (1) ferramentas médicas de prevenção ao suicídio e (2) ferramentas sociais de prevenção ao suicídio.

Os registros médicos de pacientes, hoje majoritariamente em formato digital (RME registros médicos eletrônicos, e RHE - registros hospitalares eletrônicos), estão cada vez mais acessíveis por meio de sistemas de informação integrados. Isso é particularmente o caso em países como o Reino Unido, que possui um sistema único de saúde moderno e digital. Também no Brasil existe um movimento nesse sentido. Em 2018, a Câmara dos Deputados aprovou regras para a digitalização sistemática dos registros médicos brasileiros, instituindo uma certificação digital (Lei Ord. 13787/2018, DOU 28/12/18, p. 3, col. 1).

Outra grande base de informações, cujo uso é mais controverso, consiste nas plataformas virtuais, também chamadas de mídias ou redes sociais - Facebook, Twitter, Instagram, Tik Tok, Reddit, Tumblr, Strava, Fitbit - pelas quais as pessoas compartilham informações sobre estados emocionais, frustrações, planos imediatos, atividades recentes etc. Google e Apple dispõem de relevantes dados quanto aos hábitos de navegação dos usuários, como por exemplo a incidência de termos de busca 'como cometer suicídio' ou 'como me matar'. Essa imensa base de dados é notavelmente mais extensa (ainda que qualitativamente mais rasa) do que a anterior, pois inclui indivíduos que não procuram atendimento médico.

D’Hotman et al resumem de forma otimista as possibilidades que surgem da aplicação de IA a essas bases de dados: "A análise desses conjuntos complexos de informações [...] pode fornecer um instantâneo do estado biológico, social e psicológico de uma pessoa [...] permitindo a detecção de padrões [...]" e otimisticamente enunciam: "A IA está bem posicionada para enfrentar o desafio de navegar por grandes bancos de dados para a prevenção do suicídio" (2020, p. 1). No caso das ferramentas médicas (1), os autores propõem o desenvolvimento de algoritmos capazes de identificar a partir de fontes oficiais (em sua maioria RME e RHE) padrões de comportamento que podem indicar risco elevado de suicídio. Trata-se de ferramentas de detecção que utilizam os mesmos dados ao alcance do médico, mas os interpreta de forma mais sistêmica e abrangente. A IA pode assim identificar padrões que seriam indecifráveis a partir de estudos estatísticos tradicionais. Essas ferramentas auxiliariam o corpo médico a tomar decisões importantes, como se e quando intervir de forma paternalista na prevenção ao suicídio.

Experimentos iniciais corroboram o otimismo quanto à eficácia dessas ferramentas. Walsh et. al (2017) aplicaram algoritmos de detecção ao suicídio alimentados com dados de RHE e obtiveram de forma experimental, precisão de 80 a $90 \%$ na detecção de tentativas de suicídio durante um período de observação de dois anos. No caso de tentativa iminente de suicídio a precisão obtida foi de $92 \%$. Esses são experimentos virtuais, com dados passados, e testes retroativos. Embora a aplicação clínica dessas ferramentas não tenha sido ainda amplamente testada, não resta dúvida de que seu uso pareça promissor. Experimentos iniciais com o uso de IA em modelos preditivos evidenciam outra vantagem que contribui para a eficácia: a identificação de novos fatores de risco. A insônia, por exemplo, tem sido apontada pelos algoritmos como um fator importante de risco de suicídio (POMPILI et al., 2013).

No caso de (2), ferramentas sociais de detecção, trata-se do desenvolvimento de algoritmos capazes de interpretar linguagem natural, ou seja, dados provenientes de 'posts' ou trocas de mensagens em mídias sociais, bem como termos inseridos em mecanismos de busca virtual. É comum que potenciais suicidas procurem na Internet por informações referentes a técnicas capazes de causar a própria morte ou que revelem nas suas plataformas pessoais suas angústias mais profundas ou mesmo despedidas. Por essa mesma razão, Facebook, Google e Apple

MAAR, Alexander. 'É para o seu próprio bem': a dimensão ética das ferramentas de detecção de risco de suicídio e da intervenção paternalista. Griot : Revista de Filosofia, Amargosa-BA, v.22 n.1, p.95-116, fevereiro, 2022. 
usam informações provenientes dos usuários de suas respectivas plataformas para identificar indivíduos em risco e implementar estratégias de intervenção, como o fornecimento de linhas diretas e informações sobre como encontrar ajuda.

Aqui devemos tecer um comentário importante. É preciso que instrumentos de ajuda disponíveis aos suicidários estejam livres de qualquer monitoramento por meio de IA. Linhas diretas como o Centro de Valorização da Vida (CVV) garantem o anonimato de quem escolhe fazer uso do serviço, ou seja, garantem a ausência de mecanismos de detecção (risco zero). Essa garantia dá ao usuário a confiança necessária para se abrir sobre seus sentimentos, e expandir sua visão crítica de si mesmo e de seus problemas. Esses são indivíduos que se reconhecem como em risco, e procuram ajuda. A vigilância paternalista, ainda que com vistas à beneficência, poderia ter um efeito negativo na capacidade de autocompreensão do tentante.

Poder-se-ia especular, com propriedade, que o monitoramento por IA de redes sociais seria um inibidor; indivíduos preocupados com eventual detecção evitariam exprimir seus sentimentos, não sendo assim detectados pelas ferramentas algorítmicas. Esse seria um efeito colateral indesejável da estratégia, e somente a experimentação empírica poderá confirmar seu real impacto. Mas devemos lembrar que uma das causas para a ampla difusão do uso dessas plataformas é precisamente a possibilidade de expor subjetividades e carências psicológicas. $\mathrm{O}$ desejo de exposição facilita a identificação de sujeitos ambivalentes, ou que desejam, ainda que de forma não consciente, ser detectados como em risco (cry for help). Contudo, o suicida racional não ambivalente e consciente da ação de monitoramento possivelmente escaparia à detecção.

D’Hotman et al (2020) acreditam que (1) bases de dados médicos, e (2) bases de dados sociais, possam ser eventualmente combinados, assegurando maior eficácia na detecção de risco, sem desencadear um grave problema ético. Uma das formas mais óbvias de se fazer isso seria buscar o consentimento dos usuários dos serviços. É razoável supor que após uma ampla campanha de esclarecimento das dificuldades das ferramentas bioestatísticas tradicionais em detectar risco - a depressão, por exemplo, é uma doença multidimensional e por vezes de difícil detecção - muitos dariam sua anuência.

Ferramentas algorítmicas de detecção de risco de usuários de redes sociais já existem, mas são iniciativas de empresas privadas, e por isso temos poucas informações sobre elas. $\mathrm{O}$ Facebook, por exemplo, retém em sigilo os dados sobre a eficácia de seus métodos de detecção e intervenção. As estratégias adotadas variam dependendo do grau de risco identificado pelo algoritmo. Em casos de alto e imediato risco, as equipes do Facebook podem ligar diretamente para os serviços de emergência, que por sua vez possuem a capacidade de intervir de forma direta e não solicitada a fim de preservar a vida. Estatísticas precisas não foram divulgadas, mas é certo que intervenções diretas já ocorrem em função de detecção exclusiva por IA (D'HOTMAN et al, 2020).

Já sobre a eficácia dessas ferramentas existem alguns dados importantes, ainda que preliminares. Coppersmith et al. (2018) aplicaram algoritmos para interpretar a linguagem natural usada em mídias sociais para determinar risco de suicídio. As estimativas foram então cruzadas com informações obtidas, sob prévio consentimento, de RME e RHE, que informavam se os indivíduos haviam tentado suicídio durante o período em questão. A conclusão dos autores foi de que o algoritmo era até dez vezes mais preciso (entre $40 \%$ e $60 \%$ ) na detecção de risco do que os médicos que atenderam esses pacientes clinicamente (entre $4 \%$ e $6 \%$ ). 0 período analisado variou de um a seis meses.

Em um tom menos otimista sobre a potencial utilidade dos dados obtidos das ferramentas de navegação, Ma-Kellams (2015) argumenta que o uso desses mecanismos de detecção é mais acurado e prevalente entre indivíduos de extratos econômico-sociais elevados e que minorias

MAAR, Alexander. 'É para o seu próprio bem': a dimensão ética das ferramentas de detecção de risco de suicídio e da intervenção paternalista. Griot : Revista de Filosofia, Amargosa - BA, v.22 n.1, p.95-116, fevereiro, 2022. 
raciais e grupos economicamente desprivilegiados tendem a ter seus perfis de risco calculados de forma incorreta. Isso é amparado por estudo empírico (MA-KELLAMS e al., 2016) que procurou verificar a eficácia das ferramentas do Google em relação à detecção de risco. Os autores perceberam que a estimativa do risco de suicídio foi assimétrica entre diferentes regiões dos Estados Unidos, com maior incidência de erro nos estados com grupos maiores de minorias raciais e menores níveis socioeconômicos. Ainda sobre o poder preditivo dessas ferramentas, a autora salienta que previsões de curtíssimo prazo são mais confiáveis, 'vigiando' os fenômenos na medida em que ocorrem ou estão prestes a ocorrer e conclui que "big data pode ser mais bem consumida junto com - e não no lugar de - 'pequenos' dados [informações granulares, tais como achados clínicos]" (MA-KELLAMS, 2015).

\section{Eficácia vs dano moral}

Os dados positivos, ainda que provisórios, sobre a precisão de tais ferramentas sugerem que em breve haverá uma integração maior dessas estratégias com as práticas clínicas tradicionais. Mas a permissibilidade do uso dessas informações por IA, sobretudo, sem o consentimento expresso dos usuários das plataformas digitais, suscita uma série de considerações éticas importantes e vários riscos já foram identificados por organismos como o Data Ethics Framework do governo britânico, o AI Australia's Ethics Framework. A utilização de ferramentas inteligentes de detecção médicas e sociais, novamente, sem consentimento prévio claramente expresso, parece ferir direitos assegurados por importantes convenções e legislaturas.

No Brasil, a Constituição de 1988, art. 5, X, assegura que "são invioláveis a intimidade, a vida privada, a honra e a imagem das pessoas, assegurado o direito a indenização pelo dano material ou moral decorrente de sua violação" (BRASIL, 1988). Já o Marco Civil da Internet, Lei n. 12.965/2014, garante no artigo $3^{\circ}$, II e III, a proteção à privacidade e aos dados pessoais. Já a ilicitude de divulgação de dados sensíveis de internet relativos à orientação sexual, saúde e religião está amparada no Brasil pela recém-criada Lei nº 13.709/18 (Lei de Proteção de Dados - LGPD), em vigor desde agosto de 2020 .

Em âmbito internacional, o artigo $8^{\circ}$, I, da European Convention for the Protection of Human Rights and Fundamental Freedoms garante que todos têm assegurados o direito ao respeito da vida privada e familiar, do domicílio e da correspondência. Outras convenções e legislações fazem afirmações similares, como o Privacy Act nos Estados Unidos (1974), o Bundesdatenschutzgesetz na Alemanha (1978) e a European Union's Directive on Data Protection, na União Europeia (1995).

Dada a potencial quebra de sigilo e invasão de privacidade ocasionada pelo uso dessas ferramentas, argumentos em favor do uso de AI precisam demonstrar que essas infrações são de interesse e claro benefício público e que os danos produzidos podem ser controlados e minimizados. Claramente, a permissibilidade desses programas dependeria de sua comprovada eficácia avaliada e supervisionada por órgãos independentes.

Algoritmos, assim como humanos, cometerão erros: falsos positivos e falsos negativos. No primeiro caso, trata-se de implementar uma intervenção em indivíduo não suicida, causando dano às suas liberdades civis e produzindo condições para trauma psicológico e estigma social. No caso do segundo, o resultado pode ser a morte do sujeito que passou intacto pelos mecanismos de detecção. Defensores da IA dirão que erros semelhantes acontecem por meio das ferramentas de bioestatística tradicionais e que comparativamente não haveria razão para se abandonar as novas ferramentas - desde que a eficácia superior fosse continuamente verificada.

MAAR, Alexander. 'É para o seu próprio bem': a dimensão ética das ferramentas de detecção de risco de suicídio e da intervenção paternalista. Griot : Revista de Filosofia, Amargosa - BA, v.22 n.1, p.95-116, fevereiro, 2022. 
Todavia, é importante lembrar mais uma vez que ferramentas de IA são calibradas para 'preferir' o erro com consequências clínicas menos graves - uma versão digital do 'errar para o lado da vida'. Embora essas ferramentas sejam potencialmente superiores na detecção de risco ao suicídio, é quase certo que o número absoluto de intervenções paternalistas não justificadas seja expressivo. Estudos preliminares apontam precisamente para isso (CARTER et. al., 2017). McKernan et al (2018) sustentam ainda que modelos de risco para eventos como o suicídio dependem da detecção de muitos falsos positivos para a identificação de um verdadeiro positivo. Isso oferece um contraponto à proposição de que mecanismos de IA oferecem eficácia superior. Talvez seja o caso de dizer que oferecem maior eficácia na detecção de risco real de suicídio, deixando passar poucos falsos positivos, às custas de mais falsos positivos.

Os dados são preliminares. Todavia, será necessário demonstrar que apesar dos falsos positivos o benefício alcançado pelas novas ferramentas é superior ao dano moral produzido. É necessário demonstrar que o custo-benefício obtido por mecanismos de detecção com base em IA é superior ao custo-benefício dos mecanismos de detecção tradicionais. Parece preferível pensar no uso desses instrumentos como complementares à prática médica, e não um sistema independente, e cuidadosamente regulamentados pela administração pública. Esse não é o caso quando o algoritmo de uma empresa privada, como o Facebook, encaminha uma viatura policial à casa do usuário identificado em risco. McKernan et al asseveram: "Todas essas ações [interventivas] têm implicações de potencial hospitalização voluntária ou involuntária e consequências para a autonomia e privacidade do paciente" (2018, p. 3).

D’Hotman et al (2020) sustentam que qualquer intervenção seja 'proporcional' ao grau de risco de suicídio identificado pelo algoritmo. O princípio da proporcionalidade sugere que a intervenção autoritária é justificada apenas quando aplicada a indivíduos considerados de alto risco - embora não assegure que essa seja a melhor opção do ponto de vista ético. Para esse efeito os autores conciliam a questão da proporcionalidade com um princípio ético, o da 'alternativa menos restritiva'. Esse princípio, cujo uso em políticas de saúde pública foi popularizado por Childress et al., determina que "intervenções infrinjam o mínimo necessário os direitos e liberdades individuais para que se alcance o objetivo de uma política de saúde pública" (2002, p. 173). Mas há um fator complicador. O princípio da alternativa menos restritiva estabelece que a intervenção menos infratora é preferível apenas quando comparada a alternativas igualmente eficazes. Assim, teríamos de comparar a alternativa 'internação forçada', com outras igualmente eficazes, o que é notoriamente difícil, uma vez que a restrição total de liberdade não pode ser rivalizada na capacidade de satisfação do objetivo 'prevenir o suicídio'. Não havendo alternativas igualmente eficazes, o princípio não se aplica.

Há que se considerar também qual a ambição, em termos de redução do número de suicídios, da política de saúde pública e as consequências éticas de sua implementação. Digamos que o objetivo a ser alcançado seja diminuir a incidência populacional de suicídios em 10\%. Talvez, na busca por esse objetivo modesto, os direitos civis sejam apenas minimamente desrespeitados e intervenções paternalistas sejam conduzidas em pequeno número. Contudo, se o objetivo for mais audacioso, digamos $90 \%$ de redução, então a menor infração necessária para produzir os efeitos desejados poderia implicar em erosão considerável das liberdades civis. Isso seria particularmente verdadeiro no caso dos falsos positivos submetidos a intervenções desnecessárias e dos suicidas racionais e autônomos submetidos a repetidas e duradouras intervenções. Objetivos ambiciosos já existem, como evidenciado pelo programa norte americano Zero Suicide.

McKernan et al corretamente assinalam que os algoritmos são necessários para identificar pessoas em risco que passariam despercebidas de outra forma. A implementação desses

MAAR, Alexander. 'É para o seu próprio bem': a dimensão ética das ferramentas de detecção de risco de suicídio e da intervenção paternalista. Griot : Revista de Filosofia, Amargosa - BA, v.22 n.1, p.95-116, fevereiro, 2022. 
novos métodos precisa ser "combinada com uma estrutura ética para garantir que os benefícios superem os riscos" $(2018$, p. 4). Isso é mais facilmente realizável no caso de ferramentas de detecção médicas e os autores sugerem que além da solicitação de consentimento dos pacientes, exista uma cláusula de revogação posterior de consentimento - com o que concordamos.

Allen e Selgelid (2017) sugerem que em vez de exigir que as intervenções satisfaçam a uma condição necessária (como a de ser a alternativa menos invasiva), seria mais útil avaliarmos o grau em que intervenções alcançam diferentes desideratos éticos. Eles propõem que pensemos em:

[...] dimensões escalares nas quais as intervenções poderiam sair-se melhor ou pior [...] As intervenções de saúde pública são eticamente aceitáveis na medida em que sejam eficazes, proporcionais, necessárias / menos infratoras e publicamente justificadas. Em vez de determinar se qualquer intervenção é eticamente aceitável ou não, tal estrutura localizaria qualquer intervenção em uma escala que varia desde aquelas que são mais eticamente aceitáveis (aquelas que se saem melhor em todas as dimensões) até aquelas que são eticamente inaceitáveis (aquelas que têm pior desempenho em todas as dimensões). Tal estrutura [...] poderia permitir um forte desempenho em algumas dimensões para compensar o desempenho abaixo do ideal em outras (ALLEN; SELGELID, 2017, p. 534).

A abordagem multidimensional proposta por Allen e Selgelid não reduz a permissibilidade moral de intervenções paternalistas à satisfação de qualquer objetivo de políticas de saúde pública. Eficácia, proporcionalidade, menor violação de direitos e justificativa pública são diferentes dimensões nas quais o desempenho de uma ação intervencionista em termos de custo-benefício poderia ser considerado melhor ou pior. Esse desempenho relativo é influenciado diretamente pela forma como tais ferramentas são utilizadas. Ferramentas médicas são menos problemáticas do que as sociais, pois em geral contam com o consentimento. $O$ mesmo não ocorre no caso de ferramentas preditivas sociais desenvolvidas por empresas privadas não regulamentadas (ou em vias de regulamentação). Uma das questões mais salientes no momento é a necessidade de se proporcionar à população e ao poder público maior transparência sobre a eficácia dos mecanismos de detecção e prevenção usados por empresas como Google e Facebook.

\section{Transparência}

O problema da transparência de dados e ferramentas não se apresenta de forma tão pronunciada no desenvolvimento de ferramentas de predição médicas. Isso porque além do já mencionado consenso dos pacientes, pesquisas nessas áreas contam com supervisão independente de comitês de ética dedicados a proteger os três princípios básicos da atividade médica: autonomia, beneficência e não maleficência. Contudo, riscos existem, como a possibilidade de que algoritmos que se utilizam de dados médicos serem reconfigurados para fins menos nobres do que prevenção ao suicídio, como ajudar os sistemas de saúde a economizar recursos (CHAR; SHAH; MAGNUS, 2018).

Mas as complexidades éticas são certamente mais pronunciadas no caso de dados sociais. As redes sociais, em suas origens, contavam apenas com a cooperação dos usuários em reportar conteúdos impróprios e perigosos aos gestores das plataformas. A participação de indivíduos e entidades não ligados à empresa era estimulada. Esse estímulo permanece, mas a dependência da participação do usuário não existe mais. Na ocasião do World Suicide Prevention Day, o Facebook divulgou que:

MAAR, Alexander. 'É para o seu próprio bem': a dimensão ética das ferramentas de detecção de risco de suicídio e da intervenção paternalista. Griot : Revista de Filosofia, Amargosa - BA, v.22 n.1, p.95-116, fevereiro, 2022. 
De abril a junho de 2019, agimos em relação a mais de 1,5 milhão de posts sobre suicídio e automutilação no Facebook encontrando mais de 95\% antes que fossem relatadas por usuário. Durante o mesmo período, agimos sobre 800 mil posts com conteúdo análogo no Instagram, encontrando mais de $77 \%$ antes de ser relatado por usuário (HUTCHINSON, 2019).

A implementação de AI nas ferramentas de detecção é uma realidade. Para garantirmos a confiança do público nessas novas ferramentas, seria importante instaurarmos um diálogo aberto e educativo com a população sobre os benefícios, mas também os riscos dessa tecnologia. Um dos principais desafios do momento é combater a falta de regulamentação que existe na implementação dessas estratégias de prevenção no setor privado. Isso porque "...há uma importante e evidente tensão entre identificar pessoas em risco iminente de suicídio e anonimizar dados individuais" (D'HOTMAN et al, 2020, p. 3).

Devemos ainda ter particular cuidado com certos grupos minoritários nos quais a incidência de fatores de risco costuma-se apresentar elevada, tais como pessoas LGBT, indígenas ou jovens aos cuidados de conselhos tutelares (UNITED STATES, 2012). Esses grupos podem ser desproporcionalmente afetados por algoritmos calibrados para salvar vidas às custas de falsos positivos. Essa intervenção pode expor uma pessoa à sua família, e não apenas no que concerne a sua contemplação do suicídio, mas também a outros flertes, como pensamentos e comportamentos proibidos pelos familiares. Consequentes intervenções não justificadas têm o potencial de reforçar estigmas e promover maior exclusão social e desconfiança das políticas públicas. A fim de minimizar esses riscos é imprescindível que ferramentas de detecção social como as do Facebook sejam mais transparentes e acessíveis, permitindo-se a colaboração com a comunidade acadêmica (BARNETT; TOROUS, 2019). Todavia, a transparência desses mecanismos de detecção poderia facilitar o desenvolvimento de mecanismos de camuflagem de coisas piores do que o pensamento suicida: o incitamento ao suicídio. Isso ocorreu nos casos do desafio da baleia azul, fenômeno surgido na rede social russa VK, associado ao suicídio de adolescentes. Evidencia-se aqui a necessidade de constante desenvolvimento dos sistemas a fim de impedir tais mecanismos.

Há um custo para a criação e implementação dessas estratégias, premissa básica do argumento de que tais ferramentas constituem propriedade intelectual dos desenvolvedores. Contudo, o argumento que estipula a permissibilidade da quebra de sigilo, invasão de privacidade e intervenção restritiva para a prevenção do suicídio tem como premissa básica a noção de que o interesse público possui prioridade. A concordância com essa posição conduz invariavelmente à conclusão de que se o interesse público na defesa da vida se sobrepõe a certas garantidas de direitos individuais, também o interesse público na transparência das ferramentas de prevenção sobreporse-á ao direito à propriedade intelectual das corporações privadas. Entendemos que uma eventual defesa da falta de transparência com base no direito à propriedade é argumento refutável.

Parece haver um constante equilíbrio entre o desenvolvimento de mecanismos de prevenção mais eficazes e a proteção às liberdades individuais - como o direito à privacidade. Ao longo do artigo argumentamos que violações limitadas e pontuais de algumas dessas liberdades parecem bem justificadas no caso do risco de suicídio, pois se propõem a defender e restaurar as condições nas quais o indivíduo pode experimentar autonomia profunda. Defensores das novas estratégias dependentes de IA parecem acreditar que tal equilíbrio é possível:

Um sistema pode proteger os indivíduos da identificação externa, garantindo forte proteção técnica, estrutura de governança rigorosa e treinamento/supervisão para a equipe com acesso aos dados [...] o controle de acesso aos dados pode ser mediado por um computador em um ambiente de informações distribuídas, usando tecnologia de block chain [...] Tais esforços diminuiriam a probabilidade de liberação não intencional de

MAAR, Alexander. 'É para o seu próprio bem': a dimensão ética das ferramentas de detecção de risco de suicídio e da intervenção paternalista. Griot : Revista de Filosofia, Amargosa - BA, v.22 n.1, p.95-116, fevereiro, 2022. 
informações pessoais [...] separando a análise dos dados de seus identificadores (D'HOTMAN et al, 2020, p. 3).

A citação ilustra como grandes empresas de tecnologia tradicionalmente respondem a desafios éticos: salientam a necessidade de desenvolvimento de novas tecnologias capazes de supervisionar as primeiras, formas de nos proteger de ameaças cujo surgimento as próprias empresas propiciaram. Essa estratégia tem duas consequências negativas.

- Coloca mais poder e centralidade de decisão nas mãos de empresas privadas. É ingênuo esperar que a autorregulamentação por meio de comitês de ética internos seja capaz de proteger as liberdades civis sem adequada supervisão e regulamentação governamental e da sociedade civil.

Em 2020, o Facebook concordou em uma limitada transferência de poder para uma organização independente (oversight board) formada por defensores da livre expressão: um jornalista, um ex-primeiro-ministro, um vencedor do prêmio Nobel e professores de direito (CARRIEW, 2020). Não se trata de inciativa voluntária e generosa. É uma resposta a inúmeros problemas de desrespeito à privacidade dos usuários ocorridos em tempos recentes.

- Embora do ponto de vista técnico a separação entre bancos de dados e identificadores faça sentido, a estratégia tende a gravemente subestimar a ação de hackers que teriam interesse na quebra desse sigilo para fins nefastos.

Não se trata de hipótese remota. Em 2018, o Facebook foi vítima de um importante ataque cibernético que expôs informações confidenciais e sensíveis de, no mínimo, 50 milhões de pessoas (MATSAKIS; LAPOWSKI, 2018). O Instagram é vítima frequente de ataques cibernéticos. Esses ataques não são apenas oriundos de criminosos isolados. Operation Aurora, em 2009, por exemplo, consistiu em uma série de ataques hackers conduzidos por grupos bem financiados, como o Elderwood Group - baseado em Pequim e associado com o Exército de Libertação Popular. Entre as empresas atacadas estavam Google e Yahoo. Em anos mais recentes, Cambridge Analytica protagonizou grande escândalo após vir a público, em 2018, que dados de usuários do Facebook foram tomados sem consentimento para uso em estratégias de campanhas políticas - como a que culminou na eleição de Donald Trump, em 2016 (CONFESSORE, 2018). As estratégias de machine learning usadas nesses casos não difere muito dos algoritmos usados na prevenção ao suicídio.

\section{Observações finais}

Ao longo deste artigo tecemos diversas considerações históricas, éticas e médicas acerca do suicídio. Inicialmente exploramos o fato de que embora haja discordância filosófica importante sobre o direito ao suicídio e o dever de intervenção, há possibilidade de consenso sobre alguns pontos importantes. Primeiramente, parece muito bem documentada a relação causal entre doença psíquica e comprometimento de capacidade de deliberação autônoma em benefício próprio, como é o caso de indivíduos acometidos por depressão profunda ou toxicodependentes. Chamamos a esses casos patológicos de suicidas não racionais e concluímos que intervenções nesses casos são amplamente justificadas. A não intervenção consistiria em negligência médica.

No caso do suicida racional existe um conflito entre respeito à autonomia e necessidade de ação em defesa da vida. Esse conflito é capturado pelo embate entre diferentes tradições filosóficas. Contudo, fatores complicadores como ambivalência, fazem a balança pender para o lado da proteção à vida. Defendemos que intervenções paternalistas pontuais e de curta duração são bem justificadas mesmo no caso do suicida racional. Para tanto, é vital a distinção entre autonomia superficial e profunda. A intervenção intende restaurar as condições para que a

MAAR, Alexander. 'É para o seu próprio bem': a dimensão ética das ferramentas de detecção de risco de suicídio e da intervenção paternalista. Griot : Revista de Filosofia, Amargosa - BA, v.22 n.1, p.95-116, fevereiro, 2022. 
autonomia profunda possa florescer sem comprometimentos - trata-se de uma defesa da autonomia futura.

Podemos resumir nossa posição da seguinte forma: o paternalismo pontual associado a políticas de saúde pública se apresenta como uma posição bem justificada, sobretudo se levarmos em conta: (1) a relação entre suicídio e distúrbios do humor, (2) o comportamento ambivalente frequentemente apresentado por suicidas (cry for help), (3) a dificuldade em distinguirmos suicidas racionais e não racionais, (4) a necessidade dos sistemas de saúde de minimizar os danos à população a partir de estratégias de prevenção qualificadas como 'errar para o lado da vida', (5) a relação entre saúde e autonomia profunda.

Havendo decidido em favor da intervenção, mesmo a coercitiva se for o caso, passamos a nos dedicar às estratégias e ferramentas disponíveis para detecção de indivíduos e grupos em risco de suicídio. $\mathrm{O}$ uso de $\mathrm{AI}$ aplicado a bases de dados sociais e médicos dá mostras precoces de grande eficácia em detecção. Contudo, a geração de muitos falsos positivos coloca em risco as liberdades individuais de sujeitos que afinal de contas não deveriam sofrer intervenção. A não regulamentação das ferramentas sociais de detecção (diferentemente das médicas que são amplamente regulamentadas) nas mãos de empresas privadas, também é fonte de preocupação. Aprimorar a transparência de ferramentas e bases de dados, bem como transferir poder de decisão a entidades públicas terceiras, são formas de se minimizar esses problemas. Mas os perigos não devem ser subestimados, sobretudo, a questão da manutenção do sigilo dos dados e o impacto negativo em certos grupos minoritários mais impactados por essas tecnologias.

Além da regulamentação governamental e vigilância por entidades independentes, deveria haver um mecanismo de exclusão de qualquer forma de individuação e identificação por varredura algorítmica. Além de constituir uma defesa apropriada das liberdades individuais, o mecanismo aumentaria a confiança da população em tais sistemas. Os indivíduos que lançassem mão dessa opção continuariam a ser monitorados pelas ferramentas bioestatísticas tradicionais e a partir da interação pessoal paciente-médico, possivelmente com eficácia preditiva reduzida. Todavia, em termos populacionais, a não identificação desses indivíduos não teria repercussão negativa na capacidade preditiva dos algoritmos, de modo que estratégias e campanhas de prevenção ao suicídio poderiam guiar-se por resultados estatísticos obtidos de forma ética.

MAAR, Alexander. 'É para o seu próprio bem': a dimensão ética das ferramentas de detecção de risco de suicídio e da intervenção paternalista. Griot : Revista de Filosofia, Amargosa - BA, v.22 n.1, p.95-116, fevereiro, 2022. 


\section{Referências}

ABP. Suicídio - informando para prevenir. Brasília: Conselho Federal de Medicina, 2014. ALLEN, T.; SELGELID, M. Necessity and least infringement conditions in public health ethics. Medicine, Health Care and Philosophy 20, p. 525-535, 2017.

ARONSON, R. “Albert Camus". In: ZALTA, E. (Org.) Stanford Encyclopedia of Philosophy, 2017. Disponível em: https://plato.stanford.edu/archives/sum2017/entries/camus/. Acesso em: 30 nov. 2020.

BARNETT I; TOROUS J. Ethics, transparency, and public health at the intersection of innovation and Facebook's suicide prevention efforts. Ann Intern Med. 170, p. 565-566, 2019. BARRACLOUGH, B. et. alii. A Hundred Cases of Suicide. British Journal of Psychiatry, v. 125, p. $355-373,1974$.

BATTIN, M. P. The Death Debate. Upper Saddle River: Prentice Hall, 1996.

BEAUCHAMP, T. "Suicide". In: REGAN, T. (Org.) Matters of Life and Death: New

Introductory Essays in Moral Philosophy. New York: McGraw Hill, p. 83-104, 1993.

BERTOLOTE, J. M.; FLEISCHMANN, A. Suicide and psychiatric diagnosis. World Psychiatry I 3, p. 181-185, 2002.

BIGGAR, N. Aiming to Kill. London: Darton, Longman and Todd, 2004.

BRANDT, R. "The Morality and Rationality of Suicide" In: PERLIN, S. (Org.) A Handbook for the Study of Suicide. Oxford: Oxford University Press, 1975.

BRASIL. Ministério da Saúde. Trabalhando Juntos para Prevenir o Suicídio: 10/9 - Dia Mundial de Prevenção do Suicídio. 9 de setembro de 2020. Disponível em:

http://bvsms.saude.gov.br/ultimas-noticias/3286-trabalhando-juntos-para-prevenir-o-suicidio10-9-dia-mundial-de-prevencao-do-suicidio. Acesso em: 2 dez. 2020.

CAMPBELL, R.; COLLINSON, D. Ending Lives. Oxford: Basil Blackwell, 1988.

CAMUS, A. The Myth of Sisyphus. Harmondsworth: Penguin Books, 1975 [1942].

CARRIEW, J. Will Facebook's new oversight board be a radical shift or a reputational shield?

The Guardian, 7 de maio de 2020. Disponível em:

https:/www.theguardian.com/technology/2020/may/07/will-facebooks-new-oversight-board-bea-radical-shift-or-a-reputational-shield. Acesso em: $10 \mathrm{dez} .2020$.

GARTER, G.et alii. Predicting suicidal behaviours using clinical instruments: systematic review and meta-analysis of positive predictive values for risk scales. Br. J. Psychiatry 210, p. 387-395, 2017.

CAVANAGH, J. T. et alii. Psychological autopsy studies of suicide: a systematic review.

Psychological Medicine 33, p. 395-405, 2003.

CHALIHA, J.; LE JOLY, E. The Joy in Loving: A Guide to Daily Living with Mother Theresa. London: Penguin Books, 1996.

CHAR, D; SHAH, N.; MAGNUS, D. Implementing Machine Learning in Health Care Addressing Ethical Challenges. N. Engl. J. Med. 378, p. 981-983, 2018.

CHILDRESS, J. F. et alii. Public health ethics: Mapping the terrain. The Journal of Law, Medicine \& Ethics, v. 30, p. 170-178, 2002.

CHOLBI, Michael. Suicide Intervention and Non-ideal Kantian Theory. Journal Of Applied Philosophy 19, p. 245-259, dez. 2002.

CHOLBI, M. Suicide. Peterborough (CAN): Broadview, 2011.

CONFESSORE, N. Cambridge Analytica and Facebook: The Scandal and the Fallout So Far.

The New York Times, 4 de abril de 2018. Disponível em:

MAAR, Alexander. 'É para o seu próprio bem': a dimensão ética das ferramentas de detecção de risco de suicídio e da intervenção paternalista. Griot : Revista de Filosofia, Amargosa-BA, v.22 n.1, p.95-116, fevereiro, 2022. 
https:/www.nytimes.com/2018/04/04/us/politics/cambridge-analytica-scandal-fallout.html. Acesso em: 4 dez. 2020.

COPPERSMITH, G. et alii. Natural language processing of social media as screening for suicide risk. Biomed. Inform. Insights, v. 10, 117822261879286, 2018.

COSCULLUELA, V. The Ethics of Suicide Prevention. International Journal of Applied Philosophy 9, p. 35-41, 1994.

COSCULLUELA, V. The Ethics of Suicide. New York: Garland Publishing, 1995.

CURTICE, M. Article 3 of the Human Rights Act 1998: implications for clinical practice. Advances in Psychiatric Treatment, v. 14, p. 389-97, 2008.

D'HOTMAN, D. et alii. AI-enabled suicide prediction tools: ethical considerations for medical leaders. BMJ Leader. 23 de setembro de 2020.

DWORKIN, G. "Paternalism”. In: BECKER, L. (Org.) Encyclopedia of Ethics. Nova York: Garland Publishing, p. 939-942, 1992.

HILL, T. Kantian perspectives on the rational basis of human dignity. In: DÜWELL. J. (Org.) The Cambridge Handbook of Human Dignity: Interdisciplinary Perspectives. Cambridge: Cambridge University Press, p. 215-221, 2014.

HUME, D. "On Suicide". 1777. Disponível em:

https://www.open.edu/openlearn/ocw/pluginfile.php/623438/mod_resource/content/1/ofsuicide.p df Acesso em: 14 nov. 2020.

HUTCHINSON, A. Facebook Outlines Ongoing Efforts to Prevent Self-Harm to Mark World Suicide Prevention Day. Social Media Today, 11 de setembro de 2019. Disponível em: https://www.socialmediatoday.com/news/facebook-outlines-ongoing-efforts-to-prevent-selfharm-to-mark-world-suicid/562644/. Acesso em: 23 nov. 2020.

KANT, I. "A Doutrina na Virtude - Parte I". In: A Metafísica dos Costumes - contendo a Doutrina do Direito e a Doutrina da Virtude. São Paulo: Edipro, 2003, p. 263-289.

KANT, I. Crítica da Razão Prática. São Paulo: Brasil Editora, 2004.

KANT, I. Fundamentação da Metafísica dos Costumes. Lisboa: Edições 70, 2007.

KELLY, C.; DALE, E. Ethical perspectives on suicide and suicide prevention. Advances in Psychiatric Treatment 17, p. 214-219, 2011.

MA-KELLAMS, C. Searching for Suicide. Behavioral Scientist, $1^{\circ}$ de setembro de 2015.

Disponível em: https://behavioralscientist.org/google-search-suicide/. Acesso em: 4 dez. 2020.

MA-KELLAMS C.et alii. Rethinking Suicide Surveillance: Google Search Data and Self-

Reported Suicidality Differentially Estimate Completed Suicide Risk. Clin. Psychol. Sci. 4, p. 480-484, 2016.

MATSAKIS, L.; LAPOWSKI, I. Everything We Know About Facebook's Massive Security Breach. Wired, 28 de setembro de 2018. Disponível em: https:/www.wired.com/story/facebooksecurity-breach-50-million-accounts/. Acesso em: 6 dez. 2020.

MCKERNAN, L. et. alii. Protecting Life while Preserving Liberty: Ethical Recommendations for Suicide Prevention with Artificial Intelligence. Front Psychiatry 9, p. 1-5, 2018.

MILL, J. S. "Penal Code for India". In: ROBSON, J. M.; MOIR, M. (Orgs.) The Collected Works of John Stuart Mill. Toronto and Buffalo: Univ. of Toronto Press, 1986 [1838], p. 17-30.

MILL, J. S. On Liberty. Kitchener: Batoche Books, 2001 [1859].

MOWER, A. John Stuart Mill (1806-1873). 2015. Disponível em:

https://ethicsofsuicide.lib.utah.edu/selections/john-stuart-mill/. Acesso em: 16 nov. 2020.

MURRAY, A. Suicide in the Middle Ages. Volume I: The Violent against Themselves. Oxford:

Oxford University Press, 1998.

NYS, T. R. V. Paternalism in public health care. Public Health Ethics, v. 1, p. 64-72, 2008.

MAAR, Alexander. 'É para o seu próprio bem’: a dimensão ética das ferramentas de detecção de risco de suicídio e da intervenção paternalista. Griot : Revista de Filosofia, Amargosa - BA, v.22 n.1, p.95-116, fevereiro, 2022. 
OMS. Prevenção do Suicídio: Manual para Professores e Educadores, 2000.

POMPILI, M. et alii. Insomnia as a predictor of high-lethality suicide attempts. Int. J. Clin.

Pract. 67, p. 1311-1316, 2013.

RADDEN, J. Diseases as Excuses. Philosophical Studies 42, p. 349-362, 1982.

SNEDDON, A. Equality, justice and paternalism: re-centering debate about physician assisted suicide. Journal of Applied Philosophy 23, p. 387-404, 2006.

SZASZ, T. Fatal Freedom. Syracuse: Syracuse University Press, 2002.

UNITED KINGDOM. The National Confidential Inquiry into Suicide and Homicide by People with Mental Illness. University of Manchester, 2017

UNITED STATES. Department of Health and Human Services. A Supplement to Mental Health: A Report of the Surgeon General, 2001.

UNITED STATES. Office of the Surgeon General. A Report of the U.S. Surgeon General and of the National Action Alliance for Suicide Prevention. Appendix D, Groups with Increased Suicide Risk. Washington: US Department of Health \& Human Services, 2012.

VATICAN. Sacred Congregation for the Doctrine of Faith. Declaration on Euthanasia, 1980. WALSH, C. G.; RIBEIRO, J. D.; FRANKLIN, J. C. Predicting risk of suicide attempts over time through machine learning. Clin. Psychol. Sci. 5, p. 457-469, 2017.

WHO. Suicide. 2021. Disponível em: https://www.who.int/news-room/fact-sheets/detail/suicide Acesso em: 19 fev. 2022.

Autor(a) para correspondência / Corresponding author: Alexander Maar. alexander.maar@web.de

MAAR, Alexander. 'É para o seu próprio bem': a dimensão ética das ferramentas de detecção de risco de suicídio e da intervenção paternalista. Griot : Revista de Filosofia, Amargosa - BA, v.22 n.1, p.95-116, fevereiro, 2022. 